\title{
Smoking cessation
}

\author{
I A Campbell \\ Consultant Chest Physician, Llandough Hospital, Cardiff CF64 2XX, UK
}

DE Jorenby, SJ Leischow, MA Nides, SI Rennard, JA Johnston, AR Hughes, SS Smith,
ML Muramoto, DM Daughton, K Doan, MC Fiore, TB Baker

Use of nicotine replacement therapies and the antidepressant bupropion helps people stop smoking. Smokers with clinical depression were excluded from a double-blind, placebo-controlled comparison of on sustained-release bupropion (244 subjects), a nicotine patch (244 subjects), bupropion and a nicotine 9 patch (245 subjects) and placebo (160 subjects) for smoking cessation. Treatment consisted of nine $\vec{\longrightarrow}$ weeks of bupropion (150 mg per day for the first three days and then $150 \mathrm{mg}$ twice daily) or placebo, 0 as well as eight weeks of nicotine patch therapy (21 mg per day during weeks 2-7, $14 \mathrm{mg}$ per day during week 8 , and $7 \mathrm{mg}$ per day during week 9) or placebo. The target day for quitting smoking was $\tilde{0}$ usually day 8 . Point-prevalence abstinence rate at 12 months were $15.6 \%$ for placebo, $16.4 \%$ for 8 nicotine patch, $30.3 \%$ for bupropion $(p<0.001)$ and $35.5 \%$ for bupropion plus nicotine patch $(p<0.001)$. 311 subjects (34.8\%) discontinued one or both medications, 79 because of adverse effects $-6(3.8 \%)$ on placebo, 16 (6.6\%) on nicotine patches, 29 (11.9\%) on bupropion and 28 (11.4\%) on combined treatment. The most common adverse effects were insomnia and headache. Average weight gain at 7 weeks was significantly less in the combined treatment group $(1.1 \mathrm{~kg})$ than in the bupropion group $(1.7 \mathrm{~kg})$ and the placebo group $(2.1 \mathrm{~kg})$. The nicotine patch group gained $1.6 \mathrm{~kg}$. Treatment with $\cong$ sustained-release bupropion or the combination of bupropion and the nicotine patch was more effective than nicotine patch alone or placebo but there was no significant difference between bupropion alone or bupropion in combination with a nicotine patch. (N Engl J Med 1999;340:685-91)

When reading reports of studies of smoking cessation it is important to note not only which population of smokers has been studied, but also how they were recruited. Motivation is a very important factor in stopping smoking. Smokers who choose of their own volition to attend a smoking cessation clinic are likely to be more motivated to give up the habit than are smokers who by chance rather than by design find themselves in a situation where smoking cessation interventions are offered. Other population characteristics are relevant for example, patients with cardiac conditions are better at stopping smoking than are other patients. Thus, success rates of any particular strategy will not be the same across all populations of smokers. Note should also be taken of the measure of outcome. Sustained abstinence is a stronger index of successful cessation than is abstinence at any one particular point in time (point prevalence). The longer the period of sustained abstinence, the more likely it is to reflect the true cessation rate. Reputable journals will no longer accept trials which extend over a few weeks, preferring instead those which observe for a year or more and those in which sustained abstinence actually means lapse-free abstinence for $6-12$ months or more. Neither is self- reported abstinence acceptable: claims of abstinence should be verified by an objective measure such as 을 carbon monoxide level in expired air, urinary or salivary cotinine levels, carboxyhaemoglobin or plasma thio- 을 cyanate, plasma nicotine or cotinine levels, and such $\bar{N}$ validation should be performed not just at the final encounter but at as many of the follow up visits as is practicable.

The introductory article describes a trial in the USA by Jorenby et al who recruited young to middle aged $\stackrel{\bullet}{=}$ adult smokers by advertising in the media and screened $\stackrel{\Phi}{\rightarrow}$ them initially by a telephone interview, the nature of which is not described. ${ }^{1}$ Thus, it is not clear on which criteria these reasonably well motivated subjects were $\stackrel{\Phi}{\Phi}$ further selected for physical examination, electro- $\mathbb{\mathbb { D }}$ cardiography, and chest radiography. Those with "serious or unstable" cardiac, renal, hypertensive, or $\delta$ pulmonary disorders were excluded as were those with current or previous psychoses or neuroses. Treatment for nine weeks with bupropion $150 \mathrm{mg}$ twice daily, with or without nicotine patches $(21 \mathrm{mg}$ reducing to $14 \mathrm{mg}$ and then to $7 \mathrm{mg}$ ) was prospectively compared with placebo as adjuncts to advice and support in a randomised, double blind manner. Follow up sessions at 
which further advice and support were given were scheduled at 10 (end of pharmacological treatment), 12, 26 and 52 weeks. There was additional regular telephone support.

In the abstract the authors report only the point prevalence abstinence rates at 12 months but in the text they do give validated, continuous abstinence rates from the end of week 1 to 12 months (placebo $5.6 \%$; nicotine patch $9.8 \%$; bupropion $18.4 \%$; bupropion plus nicotine patch $22.5 \%$ ). The values in the three active treatment groups were significantly better than in the placebo group. Bupropion and bupropion plus nicotine patch were better than nicotine patch alone $(p<0.001)$, but there was no significant difference between the bupropion and the combined treatment groups.

Although weight gain was initially lower in the bupropion plus nicotine patch group, this effect was not significant after week 7 . Insomnia was a problem in $30-40 \%$ of patients on active treatment, dream abnormalities and skin reactions in around $16 \%$ of those on nicotine patches, nausea in just over $10 \%$ on combined treatment, and dry mouth in $10 \%$ of those receiving bupropion. Discontinuation of treatment because of adverse effects ( $9 \%$ overall) was twice as common with bupropion as with the nicotine patch.

A previous placebo controlled study of healthy young to middle aged smokers by Hurt et $a l^{2}$ examined treatment with 100, 150 and $300 \mathrm{mg}$ bupropion daily for seven weeks on a similar background of advice and support. Recruitment was via the media and telephone interview. Again, their abstract gives a comparison of point prevalence abstinence rates not of continuous abstinence. However, in the text there are data on validated, continuous abstinence up to seven weeks: for what they are worth they show that $300 \mathrm{mg}$ bupropion daily was superior to placebo and superior to the 100 mg daily dose $(24.4 \%, 10.5 \%$, and $13.7 \%$, respectively). The $300 \mathrm{mg}$ dose was not statistically superior to the $150 \mathrm{mg}$ dose which itself was not significantly better than $100 \mathrm{mg}$ daily or placebo. A significant doseresponse effect was evident at the three, six, and 12 month assessments (point prevalence). Insomnia and dry mouth were more common with bupropion.

These two studies provide evidence that an intervention consisting of bupropion plus advice and support is of benefit to young to middle aged apparently healthy smokers who were sufficiently motivated to respond to advertisements in the media and to whom further selection criteria (some specified, some not) were applied. Furthermore, bupropion appeared to be more effective than nicotine patches but there was no merit in combining the two.

The sustained success rate (10\% for nicotine patches) in the study by Jorenby et al was lower than the rates obtained in a multicentre European study where rates of around $15 \%$ were achieved in a population who were recruited via the media, who were no different in age or health status, and to whom advice and support was also given. ${ }^{3}$ The European study showed a greater effect with the $25 \mathrm{mg}$ patch than with the $15 \mathrm{mg}$ patch, but there was no benefit in extending the use from eight to 22 weeks. In another study a $44 \mathrm{mg}$ nicotine patch did no better than a patch containing $22 \mathrm{mg} .{ }^{4}$ In a metaanalysis Fiore et al found no benefit of the 24 hour patch over the 16 hour patch. ${ }^{5}$ In a Danish study of similar smokers, nicotine patches and minimal advice/ support resulted in $11 \%$ sustained validated abstinence at one year compared with $2 \%$ in those on placebo patches. ${ }^{6}$ Using repeated support given over the telephone, Westman et al reported $21 \%$ sustained validated success at six months in those who had received nicotine patches for six weeks compared with $3 \%$ for placebo. ${ }^{7}$

At the Maudsley Hospital's Smokers' Clinic, nicotine gum plus usual supportive treatment resulted in 31\% abstinence from smoking for one year compared with $14 \%$ for placebo $(\mathrm{p}<0.05) .{ }^{8}$ In high dependence smokers $\overrightarrow{\overrightarrow{\mathrm{N}}}$ $4 \mathrm{mg}$ gum was more effective than $2 \mathrm{mg}$ gum. ${ }^{9}$ Without advice and support nicotine gum was no better than $\frac{5}{\sigma}$ placebo. ${ }^{10}$ Smokers' clinics in various countries have $\overline{\bar{\rho}}$ studied nicotine nasal sprays: at the Maudsley the suc- $\mathbb{\nabla}$ cess rate of $26 \%$ at one year was superior to placebo $(10 \%), \mathrm{p}<0.01$. In Los Angeles Schneider et al were able to demonstrate superiority $(18 \%$ versus $8 \%$ ) as were Hjalmarson et al in Sweden (27\% versus $15 \%)$, $\overrightarrow{\vec{\omega}}$ but in Rekyavik the differences at one year $(25 \%$ versus $\stackrel{\omega}{\sigma}$ $17 \%)$ and at two years (19\% versus $14 \%)$ were not $\overrightarrow{5}$ statistically significant. These devices were more effective in high dependence smokers than in low dependence $x$ smokers. ${ }^{11-14}$ Nasal irritation was not infrequent but only on $1 \%$ or so discontinued the spray because of it. Another $\frac{\text { D }}{0}$ device, the nicotine inhaler, has been studied and shown to be superior to placebo by Tonnesen et al in Copen- $-\overrightarrow{.}$ hagen $(15 \% \text { versus } 5 \%, \mathrm{p}<0.02)^{15}$ and by Hjalmarson et is $a l$ in Gothenburg (28\% versus $18 \%, \mathrm{p}<0.05) .{ }^{16}$ Adding ${ }^{\infty}$

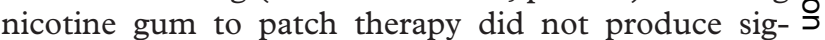
nificant differences at one year $\left.{ }^{1 / 1}\right|^{18}$ but combining nico- $\vec{\longrightarrow}$ tine nasal spray with patch therapy did improve success rates at one year (combination $27 \%$, patch alone $11 \%$, $\mathrm{p}=0.001) .{ }^{19}$

Nicotine replacement therapy (NRT) in combination $\widetilde{\sim}$ with advice and support can increase success rates. in these populations of smokers when compared with placebo or no pharmacological treatment. It can cause nausea, headaches, dizziness, disturbance in sleep and $\overline{0}$ dreams, and local irritation but there is no evidence of an increase in risk or exacerbation of cardiac problems. $\stackrel{\mathbb{Q}}{2}$ Not unexpectedly, it alleviates but does not abolish $\overrightarrow{\hat{0}}$ the withdrawal symptoms experienced after giving up 3 cigarettes. In the same sort of population bupropion produced better one year cessation rates but is less well tolerated than NRT.

\section{Smoking cessation in other populations} PRIMARY CARE

Advice from a general practitioner (GP) increases the proportion of patients intending to stop smoking and the proportion who try to stop, rather than increasing actual success rates among those intending or trying to stop; with the GP's advice to stop smoking and a warning of follow up, $5 \%$ of patients in South London were 5 abstinent a year later. ${ }^{20}$ If every GP in the UK were to $\mathbb{O}$ follow this strategy, more than half a million smokers $\underset{\omega}{\mathrm{\omega}}$ would give up. In an Oxford population advice from the GP resulted in $11 \%$ cessation, a rate which could 0 be increased by half as much again using strategies $\mathbb{\Phi}$ such as an advisory booklet, measurement of carbon? monoxide in expired air, or the offer of a visit from a health visitor. ${ }^{21}$ A more intensive advice and measurement strategy in Sydney resulted in 23\% with continuous abstinence at three years compared with $2 \%$ in $\cong$ a control group. ${ }^{22}$ Another study in New South Wales did not show a significant difference between control 8 $(1 \%)$, simple advice $(1 \%)$, and structured behavioural change $(5 \%) .{ }^{23}$ In the USA advice from primary care physicians was supplemented by nurses providing a $\stackrel{?}{?}$ pamphlet or by one of three more intensive, nurse led interventions. The latter strategies resulted in $4 \%$ cessation at one year compared with $2 \%$ in the group who were just issued with a pamphlet $(p<0.01)$; 
cessation here was defined as claimed non-smoking at three months and at one year with cotinine validation at one year. ${ }^{24}$

The addition of nicotine chewing gum to GP's advice resulted in $8 \%$ validated success at one year compared with $4 \%$ after advice plus a leaflet and warning of follow up and $4 \%$ in a control group who just completed a questionnaire. ${ }^{25}$ Unfortunately, the study did not include a group on placebo chewing gum. When placebo controlled comparisons were performed in Oxford, South Wales, and the Isle of Wight no significant advantage was found for nicotine chewing gum over placebo. ${ }^{26-28}$ Richmond et al in Sydney found no gain in adding nicotine chewing gum to a programme of structured behavioural change among patients recruited from general practice. ${ }^{29}$ Thus, the definite benefit from nicotine chewing gum in the setting of a specialised smoking cessation clinic does not extend to its use in primary care. ${ }^{30}$ However, nicotine patches used with support from practice nurses have been shown to add to the effect of GP's advice; $10 \%$ validated continuous abstinence at one year for nicotine patches compared with $7 \%$ for placebo $(p<0.05)$ in a study from Oxford $^{31}$ and $9.3 \%$ compared with $5 \%(\mathrm{p}<0.04)$ in a study by Russell et al in 15 counties. ${ }^{32}$ Eventual success rates were approximately 10 times higher among those who stopped smoking at the end of the first week than among those still smoking at one week.$^{34}$ About $15 \%$ of patients experienced significant local irritation and itching at the sites of the patches. The use of nicotine patches in primary care has been shown to be cost effective. ${ }^{35}$

HOSPITAL PATIENTS (SECONDARY/TERTIARY CARE)

Patients who attend hospital because of diseases related to smoking and who nevertheless are still smoking when seen or admitted are a group clearly different from smokers seen adventitiously in primary care or smokers who choose to attend specialised smoking cessation clinics or smokers recruited from the general population to studies of smoking cessation. Different results would be expected and, indeed, have been found.

Patients with ischaemic heart disease, especially those surviving myocardial infarction, respond better to the doctor's advice to stop smoking than do hospital patients with other diseases. ${ }^{36-40}$ Follow up support and advice more than doubled claimed abstinence at one year in $\overrightarrow{\overline{0}}$ one study. ${ }^{41}$ In a comparison of two studies conducted in a single centre where there was a programme of $x$ follow up advice and support with three other studies $\overrightarrow{\vec{F}}$ (multicentre) where there were low levels of follow up advice and support, it became evident that success rates $\frac{\bar{\sigma}}{\sigma}$ can be increased from $5 \%$ to $10 \%$ to $20 \%$ or more by $\overline{\bar{\alpha}}$ reinforcing the doctor's advice with a formal programme $\mathbb{0}$ of support and advice. ${ }^{37-3942}$ Such a programme need not be expensive and is highly cost effective. ${ }^{43}$ Postal encouragement is better than other low intensity strat- $\vec{\circ}$ egies, ${ }^{37}$ a finding which has recently been replicated outside the hospital setting. ${ }^{44}$

In Sweden at Sahlgren's hospital, nicotine gum and $\overrightarrow{\overrightarrow{0}}$ nicotine nasal spray have been shown to add to the cessation rates obtained by group therapy, but the popu- ir lations studied were mixtyres of true hospital patients of and self-referred subjects ${ }^{1:}{ }^{45}$ In the UK neither nicotine $\frac{\text { ? }}{0}$ chewing gum nor nicotine patches have proved useful 으 adjuncts to the physician's advice to hospital patients. This was true both in the context of low to minimal of support $^{42}$ and in the context of a structured programme $\infty$ of support and advice ${ }^{3 \beta^{9}}$ In the USA a well designed trial of nicotine patches which extended over 10 Veterans $\vec{\imath}$ Affairs medical centres failed to demonstrate any significant additive effect of nicotine patches over placebo $\frac{\vec{C}}{\omega}$ in 584 outpatients with ischaemic heart disease. The $\underset{N}{N}$ study did show that the patches were safe in a population 8 with cardiac disease. ${ }^{46}$ The effect of bupropion in the hospital setting has not yet been reported.

\section{Conclusions}

In the settings of smoking cessation clinics, primary $\stackrel{\mathbb{Q}}{\varrho}$ care and secondary/tertiary care, the literature over the $\overrightarrow{0}$ last 25 years provides evidence that advice to stop 3 smoking does produce beneficial effect. Reinforcing that advice with various levels of support during the initial weeks/months will improve results in all three settings. NRT adds further to success rates in the first two situations but not in hospital patients. Bupropion (not yet available in the UK) is an antidepressant of novel

\section{LEARNING POINTS}

* Advice and support are important components of successful smoking cessation strategies

* The results of smoking cessation strategies are strongly influenced by the characteristics of the populations to which they are applied

* Claims of abstinence should be validated by objective means. Outcome should be reported at a minimum of one year after the intervention with sustained, validated abstinence over: the last six months or more as the criterion of successful cessation

* Nicotine chewing gum is effective in smoking cessation clinics but not in hospital patients. In primary care the evidence for its efficacy is not conclusive. Nicotine patches are effective in smoking cessation clinics and in primary care but have not yet been demonstrated to have a significant effect in hospital patients. Nicotine nasal spray and inhaler give results little different from nicotine patches

* Bupropion has been shown to be effective in the USA in a smoking cessation clinic where subjects were recruited from the general population by advertisements in the media. It proved more effective than the nicotine patch but there was no advantage in combining the two. Studies in primary care and in hospital patients are awaited. 
pharmacological structure. ${ }^{47}$ It is as effective as NRT in the first setting but evidence of its effect in the other two is not yet available. Neither of these pharmacological agents has yet been conclusively shown to be useful when prescribed or purchased as isolated "cures for smoking". The Chancellor of the Exchequer and Parliament have the most effective "cures" at their disposal.

1 Jorenby DE, Leischow SJ, Nides MA, et al. A controlled trial of sustained-release bupropion, a nicotine patch, or both for smoking cessation. N Engl f Med 1999;340:685-91.

2 Hurt RD, Sachs DPL, Glover ED, et al. A comparison of sustainedrelease bupropion and placebo for smoking cessation. $N$ Engl $7 \mathrm{Med}$ 1997;337:1195-202.

3 Tonnesen P, Paoletti P, Gustavsson G, et al. Higher dosage nicotine patches increase one-year smoking cessation rates: results from the European CEASE trial. Eur Respir f 1999;13:238-46.

4 Jorenby DE, Smith SS, Fiore MC, et al. Varying nicotine patch dose and type of smoking cessation counselling. $\mathcal{F} A M A 1995 ; 274: 1347-52$

5 Fiore MC, Smith SS, Jorenby DE, et al. The effectiveness of the nicotine patch for smoking cessation. $\mathscr{F} A M A$ 1994;271:1940-7.

6 Tonnesen P, Norregard J, Simonsen K, et al. A double-blind trial of a 16 hour transdermal nicotine patch in smoking cessation. $N$ Engl Med 1991;325:311-5.

7 Westman EC, Levin ED, Rose J E. The nicotine patch in smoking cessation - a randomised trial with telephone counselling. Arch Intern Med 1993;153:1917-23.

8 Jarvis MJ, Raw M, Russell MH, et al. Randomised controlled trial of nicotine chewing gum. BMF 1982;285:537-40.

9 Silagy C, Mant D, Fowler G, et al. Meta-analysis of efficacy of nicotine replacement therapies in smoking cessation. Lancet 1994;343:139-42.

10 Schneider NG, Jarvik ME, Forsythe AB, et al. Nicotine gum in smoking cesssation: a placebo-controlled, double-blind trial. Addict Behav 1983; 8:253-61.

11 Sutherland G, Stapleton JA, Russell MAH, et al. Randomised controlled trial of nicotine nasal spray in smoking cessation. Lancet 1992;340: 324-8.

12 Scheinder NG, Olmstad R, Mody FV, et al. Efficiency of a nicotine nasal spray in smoking cessation: a placebo-controlled, double-blind trial. Addiction 1995;90:1671-82.

13 Hjalmarson A, Franzom M, Westin A, et al. Effect of nicotine nasal spray on smoking cessation: a randomised, placebo-controlled, double-blind study. Arch Intern Med 1994;154:2567-72.

14 Blondal T, Franzom M, Westin A. A double-blind, randomised trial of nicotine nasal spray as an aid in smoking cessation. Eur Respir f 1997; 10:1585-90.

15 Tonnesen P, Norregaard J, Mikkelsen K, et al. A double-blind trial of nicotine inhaler for smoking cessation. $¥ A M A$ 1993;269:1268-71.

16 Hjalmarson A, Nilsson F, Sjostrom L, et al. The nicotine inhaler in smoking cessation. Arch Intern Med 1997;157:1721-8.

17 Kornitzer M, Boutsen M, Dramaix M, et al. Combined use of nicotine patch and gum on smoking cessation: a placebo-controlled clinica trial. Prev Med 1995;24:41-7.

18 Puska P, Korhonem HJ, Bartiainem E, et al. Combined use of nicotine patch and gum compared with gum alone in smoking cessation: clinical trial in North Karela. Tobacco Control 1995;4:231-5.

19 Blondal T, Ludvikstottir D, Gudmundsson L et al. Nicotine nasal spray with nicotine patch for smoking cessation: a randomised trial with six-year follow-up. BMF 1999;318:285-9.

20 Russell MAH, Wilson C, Taylor C, et al. The effect of general practitioners' advice against smoking. BM7 1979;2:231-5.

21 Jamrozik K, Vessey M, Fowler G, et al. Controlled trial of three different anti-smoking interventions in general practice. BMF 1984;288:1499503

22 Richmond RL, Austin A, Webster IW. Three year evaluation of a programme by general practitioners to help patients stop smoking. BMF 1986:292:803-6.

23 Slama K, Redman S, Perkins J, et al. The effectiveness of two smokin cessation programmes for use in general practice: a randomised clinical trial. BMF 1990:300:1707-9.

24 Hollis JF, Lichtenstein E, Bot TM, et al. Nurse assisted counselling for smokers in primary care. Ann Intern Med 1993;118:521-5.

25 Russell MAH, Merriman R, Stapleton J, et al. Effect of nicotine chewing gum as an adjunct to general practitioners' advice against smoking. $\overline{\bar{\sigma}}$ BMF 1983;287:1782-5.

26 Jamrozik K, Fowler G, Vessey M, et al. Placebo controlled trial of $\bar{Z}$ nicotine chewing gum in general practice. BMF 1984;298:794-7.

27 Campbell IA, Lyons E, Prescott RJ. Stopping smoking: do nicotine $\frac{\bar{O}}{\bar{D}}$ chewing gum and postal encouragement add to doctors' advice? Practitioner 1987;231:144-7.

28 Marshall A, Raw M. Nicotine chewing gum in general practice: effect of follow-up appointments. BMF 1985;290:1397-8.

29 Richmond RL, Makinson RJ, Kehoe A, et al. One-year evaluation of three smoking cessation interventions administered by general $\overrightarrow{0}$ practitioners. Addict Behav 1993;18:187-99.

30 Lamb W, Sze PC, Sacks HS, et al. Meta-analysis of randomised controlled trials of nicotine chewing gum. Lancet 1987;ii:27-30.

31 Imperial Cancer Research Fund General Practice Research Group. Effectiveness of a nicotine patch in helping people stop smoking: results of a randomised trial in general practice. BMf 1993;306: 1304-8.

32 Russell MAH, Stapleton JA, Feyerbrand C, et al. Targeting heavy smokers in general practice: randomised controlled trial of transdermal of nicotine patches. $B M Y$ 1993:306:1308-12.

33 Stapleton JA, Russell MAH, Feyerbrand C, et al. Dose effects and predictors of outcome in randomised trial of transdermal nicotine patches in general practice. Addiction 1995;90:31-42.

34 Yudkin PL, Jones L, Lancaster T, et al. Which smokers are helped to I give up smoking using transdermal nicotine patches? Results from a is randomised double-blind placebo-controlled trial. $\mathrm{Br} \mathcal{F}$ Gen Pract 1996;46:145-8.

35 Stapleton JA, Low IN, Russell MAH. Prescription of transdermal nicotine patches for smoking cessation in general practice: evaluation of cost effectiveness. Lancet 1999;354:210-5.

36 British Thoracic Society. Smoking withdrawal in hospital patients: factors associated with outcome. Thorax 1984;39:651-6.

37 British Thoracic Society. Smoking cessation in patients: two further studies. Thorax 1990;45:835-40.

Prescott RI. Smoking cessation hospital patients given repeated advice plus nicotine or placebo chew- $N$ ing gum. Respir Med 1991;85:155-7.

39 Campbell IA, Prescott RJ, Tjeder-Burton SM. Transdermal nicotine plus support in patients attending hospital with smoking related diseases: placebo-controlled study. Respir Med 1996;90:47-51.

40 Wilcox RG, Hughes J, Rowland J. Verification of smoking history after infarction using urinary nicotine and cotinine measurements. BMF $1979 ; 2: 1026-8$.

41 Burt A, Illingworth D, Shore TRD, et al. Stopping smoking after myocardial infarction. Lancet 1974;i:304-6.

42 British Thoracic Society. Comparison of four methods of smokin withdawal in patients with smoking related diseases. BMF 1983;286: 595-7.

43 Prathiba BV, Tjeder-Burton S, Phillips C, et al. A smoking cessation counsellor: should every hospital have one? f R Soc Health 1998;118: $356-9$

44 Humerfelt S, Eide GE, Kvale G, et al. Effectiveness of postal smoking cessation advice: a randomised controlled trial in young men with reduced FEV 1 and asbestos exposure. Eur Respir F 1998;11:284-90.

45 Hjalmaron AIM. Effect of nicotine chewing gum in smoking cessatior A ranson AIM. Efrect of nicotine chewing gum in smoking cessation. A random 283

46 Joseph AM, Norman SM, Ferry LH, et al. The safety of transdermal nicotine as an aid to smoking cessation in patients with cardiac disease. nicotine as an aid to smoking ces

47 Ascher JA, Cole JO, Colin JN, et al. Bupropion: a review of its mechanism of anti-depressant activity. $\mathcal{F}$ Clin Psychiatry 1995;56:395-401. 